\title{
Compact, Frequency Reconfigurable, Printed Monopole Antenna
}

\author{
Ricardo Gonçalves, ${ }^{1,2}$ Pedro Pinho, ${ }^{1,2}$ and Nuno B. Carvalho ${ }^{1,3}$ \\ ${ }^{1}$ Instituto de Telecomunicações - Aveiro, Campus Universitário de Santiago, 3810-193 Aveiro, Portugal \\ 2 Área Departamental de Engenharia Electrónica, Telecomunicações e Computadores, Instituto Superior de Engenharia de Lisboa, \\ Rua Conselheiro Emídio Navarro 1, 1959-007 Lisboa, Portugal \\ ${ }^{3}$ Departamento de Electrónica, Telecomunicações e Informática, Universidade de Aveiro, 3810-193 Aveiro, Portugal
}

Correspondence should be addressed to Ricardo Gonçalves, rgoncalves@av.it.pt

Received 23 July 2012; Revised 29 September 2012; Accepted 19 October 2012

Academic Editor: Renato Cicchetti

Copyright ( $) 2012$ Ricardo Gonçalves et al. This is an open access article distributed under the Creative Commons Attribution License, which permits unrestricted use, distribution, and reproduction in any medium, provided the original work is properly cited.

This paper proposes a possible implementation of a compact printed monopole antenna, useful to operate in UMTS and WLAN bands. In order to accomplish that, a miniaturization technique based on the application of chip inductors is used in conjunction with frequency reconfiguration capability. The chip inductors change the impedance response of the monopole, allowing to reduce the resonant frequency. In order to be able to operate the antenna in these two different frequencies, an antenna reconfiguration technique based on PIN diodes is applied. This procedure allows the change of the active form of the antenna leading to a shift in the resonant frequency. The prototype measurements show good agreement with the simulation results.

\section{Introduction}

Antenna miniaturization is the result of the continuous search for smaller and compact electronic equipment that can present the same or even better performance.

There are many examples of techniques used for antenna miniaturization for different applications. For printed antennas, an approach is presented in [1], where a metamaterial is used between the radiating element and the ground plane of a printed circular patch, in order to reduce its resonant frequency. Another example is presented in [2], where a Koch fractal printed monopole is used to resonate at $2.5 \mathrm{GHz}$, granting a $21 \%$ reduction in size. In $[3,4]$, chip inductors are used in order to reduce the resonant frequency of printed C-monopoles, without changing the size and radiation characteristics and with minor losses to the radiating efficiency and gain. This is an interesting approach, since it is quite simple to fabricate, and it is not expensive. However it leads to narrower bandwidths.

Due to the growth of the wireless technologies and the appearance of new systems associated to communication devices, the development of interoperable devices is of great interest, and since the antennas are indispensable to wireless communication equipments, there is a great scientific interest for antennas capable of working in different frequency bands.

To achieve this goal, multiband and UWB antennas have been proposed in literature [5]. Besides these types, another possible class of radiant structures consists of the so-called reconfigurable antennas.

Reconfigurable antennas have the ability to change one or more of its radiation characteristics in real time, such as the resonant frequency, the bandwidth, the radiation pattern, or even the polarization [6]. There are different ways to achieve these changes, and different techniques have been presented, but all those techniques are based on suitable modifications of the size or shape of the antenna in order to obtain specific radiation performances.

Reference [7] shows a possibility of creating reconfigurability, using a set of printed antennas on a circular area, which is changed using a motor and thus allows the change of the resonant frequency of the structure. This solution is not very feasible because it requires the design of several printed antennas very close to each other that end up suffering from coupling and subsequently distort the radiation pattern. Besides requiring assembly and operation of an engine, this makes the structure larger and heavier. 
Another solution, smaller and more adaptable, is presented in [8-10], where MEMS (Microelectromechanical Switches), which can be activated or deactivated with a low voltage source, are employed to connect and disconnect specific elements of the antenna, so changing the overall antenna size and shape resulting in an effective change in the resonant frequency. This is a very attractive solution, given the characteristics of the MEMS; however, these are hard to fabricate and so this can be quite an expensive solution.

PIN diodes are usually inexpensive and exist in abundance on the market in various packages and configurations, which make them a versatile alternative for the implementation of reconfigurability in antennas. Nevertheless, there are few applications of PIN diodes adopted to achieve frequency reconfigurable printed antennas intended for mobile devices [11-13].

An approach to printed antenna's polarization reconfigurability is presented in [14]. Other example is presented in [15], in which, an array of antennas for a MIMO system achieve frequency reconfigurability by using PIN diodes, allowing to change the operating frequency of the antenna. Some examples on the use of PIN diodes for frequency reconfigurability in WLAN applications are presented in $[16,17]$.

The aim of this paper is to present a compact reconfigurable monopole antenna suitable to operate in the WLAN $(2.4 \mathrm{GHz})$ and UMTS $(2.0 \mathrm{GHz})$ bands using chip inductors and PIN diodes. A particular emphasis is given to the miniaturization process whose details are reported in the next section. So far, to the authors' knowledge, there are no examples published in the scientific literature adopting the mentioned devices for the proposed wireless applications.

\section{Simulation Models}

The antenna proposed in this paper is designed with two lumped components inserted in a printed monopole, in order to make it small and to allow the change in resonant frequency. To miniaturize the antenna structure, a chip inductor from Coilcraft was used. According to $[3,18]$, this element can be modeled with a series equivalent circuit composed of a series resistance $R$ and an inductor $L$, whose values depend on the frequency (see Figure 1).

Based on the expressions that describe the previous plot presented in [3] and the values presented in the inductor datasheet [18], the equivalent impedance and inductance can be calculated for the lower frequency which is where the inductor has more influence. At $2.0 \mathrm{GHz}$, this chip inductor can be modeled by an equivalent resistance $(R)$ of $1.7 \Omega$ and inductance $(L)$ of $8.2 \mathrm{nH}$.

The PIN diode used to switch the elements of the antenna is a commercial device from Avago Technologies [19]. According to [20], in forward bias the PIN diode has an equivalent circuit corresponding to an inductor in series with a resistor, while in reverse bias it results equivalent to an inductor in series with a parallel resistor and a capacitor.

The equivalent resistance of the diode decreases as the bias current increases. According to [21], the resistance has a minimum value of about $3 \Omega$ for bias currents above $10 \mathrm{~mA}$,

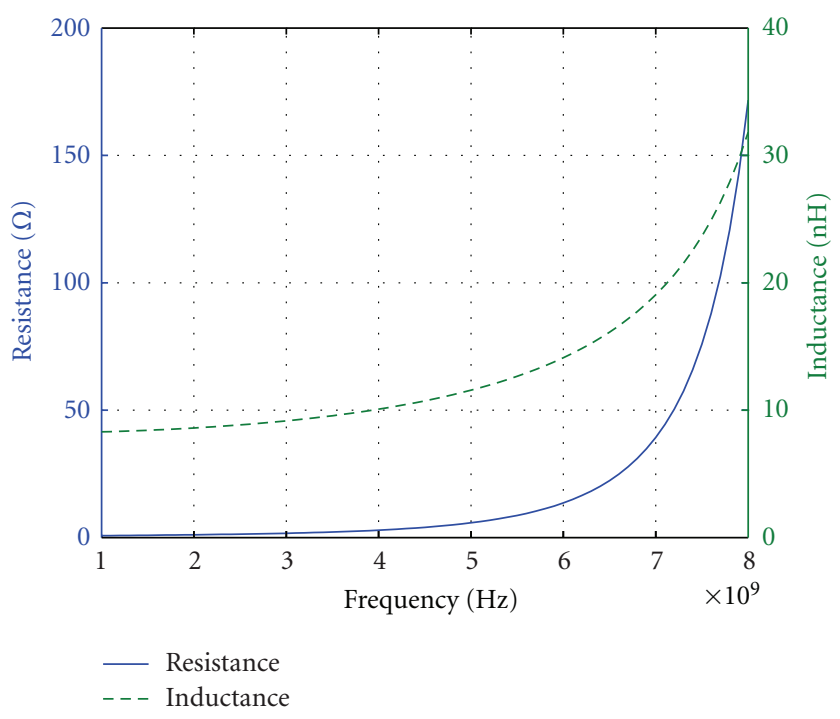

Figure 1: Chip inductor's equivalent circuit elements versus frequency.

TABle 1: Proposed antenna dimensions.

\begin{tabular}{lc}
\hline Parameter & Dimension $(\mathrm{mm})$ \\
\hline$L_{1}, L_{2}, L_{3}, L_{4}$ & $24,3.35,6.0,4.0$ \\
$L_{5}, L_{6}, L_{I}, L_{\text {gnd }}, L_{\text {sub }}$ & $13.6,5.0,1.0,21,28.5$ \\
$W_{0}, W_{1}, W_{2}$ & $3.3,1.5,1.5$ \\
$W_{\text {sub }}, \operatorname{gap}_{I}$, gap $_{D}$ & $20,0.5,2.0$ \\
\hline
\end{tabular}

and it exceeds $1 \mathrm{k} \Omega$ for bias currents near zero $(0.01 \mathrm{~mA})$. The capacitance depends upon the reverse voltage and frequency; however, its value shows small variations from $0.2 \mathrm{pF}$, for frequencies above $1 \mathrm{GHz}$. These are the values considered in the numerical simulation.

\section{Antenna Design}

The antenna proposed in this paper is a C-monopole antenna, printed upon an Arlon CuClad 217 substrate, with a relative permittivity $\left(\varepsilon_{r}\right)$ of 2.17 , a loss tangent $(\tan \delta)$ of 0.0009 and $0.787 \mathrm{~mm}$ height. The antenna geometry is presented in Figure 2, while the corresponding dimensions are presented in Table 1.

The monopole and a feeding microstrip line, which also matches the input impedance of the antenna to $50 \Omega$, are printed in the top face of the substrate and the ground plane is at the bottom face. The inductor is placed in the central arm of the monopole, while the diode is placed in the top arm as shown in Figure 2.

The area of the antenna is $20 \times 7.5 \mathrm{~mm}^{2}$, and the total area of the antenna plus the feeding line is $20 \times 28.5 \mathrm{~mm}^{2}$. The total length of the monopole, considering the diode in forward bias, is $20.95 \mathrm{~mm}$, which would correspond to a resonant frequency of $3.596 \mathrm{GHz}$, while the total length considering the diode in reverse bias is of $9.85 \mathrm{~mm}$, which would correspond to a resonant frequency of about $7.61 \mathrm{GHz}$. However, due to the introduction of the chip inductor and 


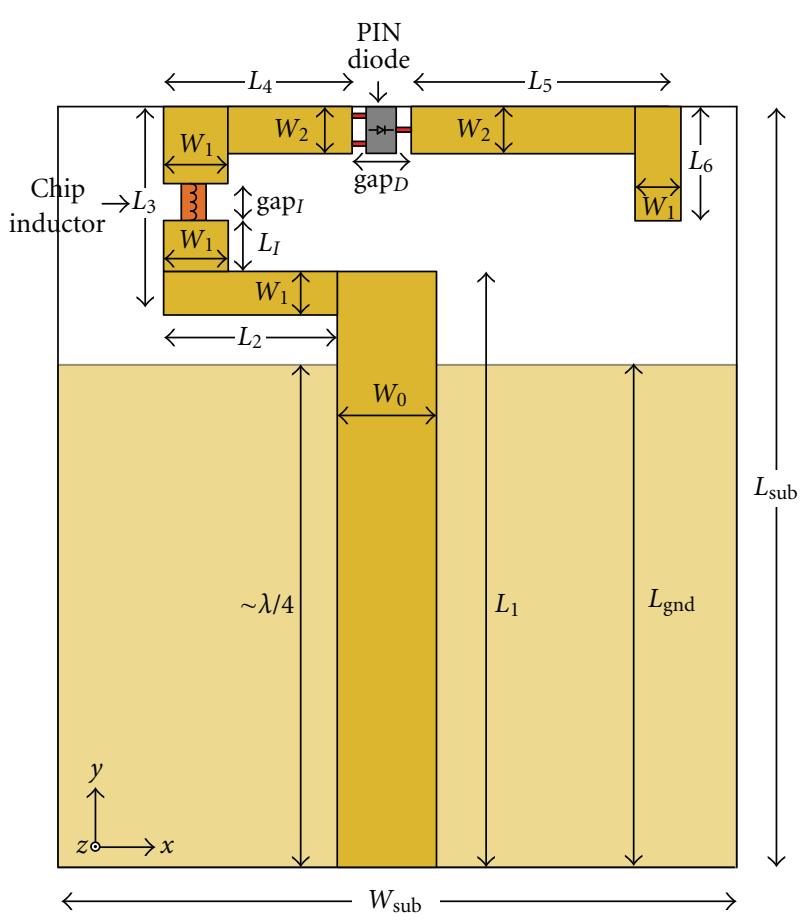

FIgure 2: Proposed antenna geometry.

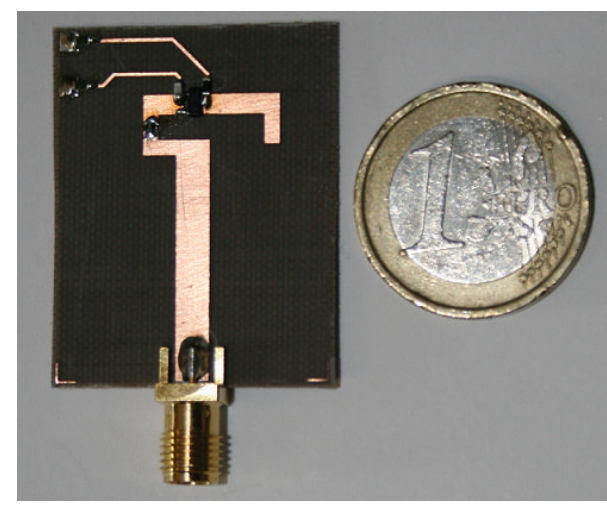

Figure 3: Prototype of the proposed antenna.

the PIN diode, the resonant frequency in both antenna configurations turns to be smaller, resulting in a reduced volume occupation.

The prototyped antenna is slightly wider than the simulated model due to the introduction of the diode polarization circuit, as can be seen in Figure 3 .

The polarization circuit of the PIN diode is a simple SPST (Single Pole Single Throw) switch configuration, as shown in Figure 4. The RF choke inductors are used to isolate the DC voltage source from the RF signal.

\section{Simulation Results}

For simulation purposes CST Microwave Studio 2011 [21] was used.

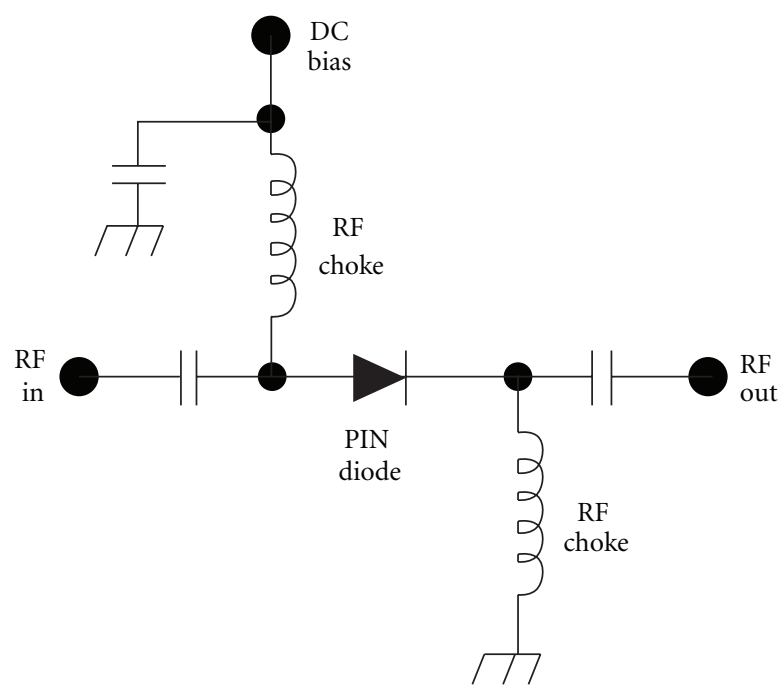

FIgURE 4: SPST circuit using a PIN diode.

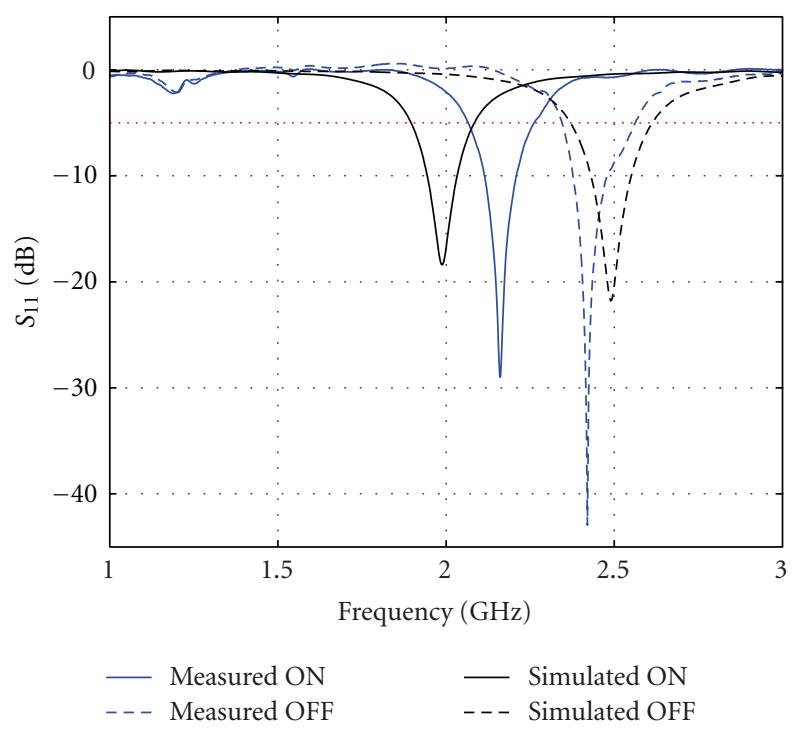

Figure 5: Simulated (black) and measured (blue) return loss for the PIN diode in "ON" (solid) and "OFF" (dashed) state.

4.1. Return Loss. Figure 5 shows the simulated and measured return loss $\left(S_{11}\right)$ for the proposed monopole antenna, considering the diode in both states of conduction.

The impedance matching is done with a $\lambda / 4$ microstrip line, which is designed for the highest frequency of operation, resulting in a higher return loss for the lowest operation band. This line was adjusted based on the numerical simulation so that both frequencies could present satisfactory result.

The definition of a small antenna is presented in [22], according to which, an antenna is considered small if $k a<$ 0.5 , where $k$ is the free-space wavenumber and $a$ is the radius of the smallest sphere which encloses the antenna. The $k a$ factor for the proposed antenna is 0.49 at the lowest working frequency, which means that this is a small antenna; in that 


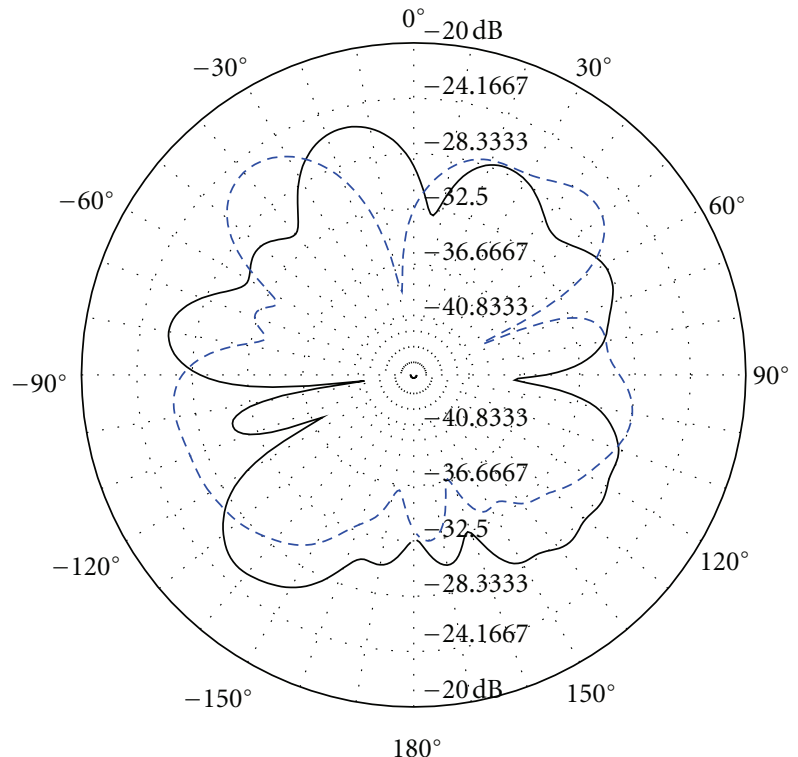

Figure 6: Measured radiation pattern at $2.2 \mathrm{GHz}$ on $X Z$ plane (blue) and $Y Z$ plane (black).

sense, the bandwidth of the antenna was considered for $S_{11}<-5 \mathrm{~dB}$.

The diode is controlled with a voltage source; the "OFF" state is the default with no power source, while the "ON" state is obtained with $3 \mathrm{~V}$ and $35 \mathrm{~mA}$.

The simulated results present a bandwidth from 1.93 to $2.17 \mathrm{GHz}$ when the diode is "ON", and from 2.4 to $2.6 \mathrm{GHz}$ when the diode is "OFF". This means that it can nearly support UMTS bands, since these are located between 1.92 to $2.17 \mathrm{GHz}$. In addition, it can support WLAN service since this band is defined between 2.4 to $2.5 \mathrm{GHz}$. The measured results present a difference to the simulated numerical results. In particular, the "OFF" band is fairly good, from 2.39 to $2.55 \mathrm{GHz}$, while the "ON" band is shifted, falling above the UMTS band.

4.2. Radiation Pattern. The measured radiation pattern for the realized prototype is presented in Figures 6 and 7, for the $X Z$ and $Y Z$ planes (see Figure 2). The connections to the polarization circuit were present inside the anechoic chamber during the measurements, which is one source of the large number of lobes in the obtained pattern.

The gain is rather small, presenting values around $0.65 \mathrm{~dB}$ at $2.4 \mathrm{GHz}$, and $0.05 \mathrm{~dB}$ for the lower frequency. These values are slightly lower when compared to a normal printed monopole; however they do not represent such a great loss. The radiation efficiency is around $77.5 \%$ at $2.0 \mathrm{GHz}$, and $80.3 \%$ at $2.4 \mathrm{GHz}$. These are fairly good values, taken into consideration the small dimensions of the antenna and the presence of the PIN diode and chip inductor.

The measured polarization was linear for the highest frequency, and elliptical for the lowest frequency.

4.3. Lumped Element Effects. The measurements performed on the realized antenna prototype shows some deviations

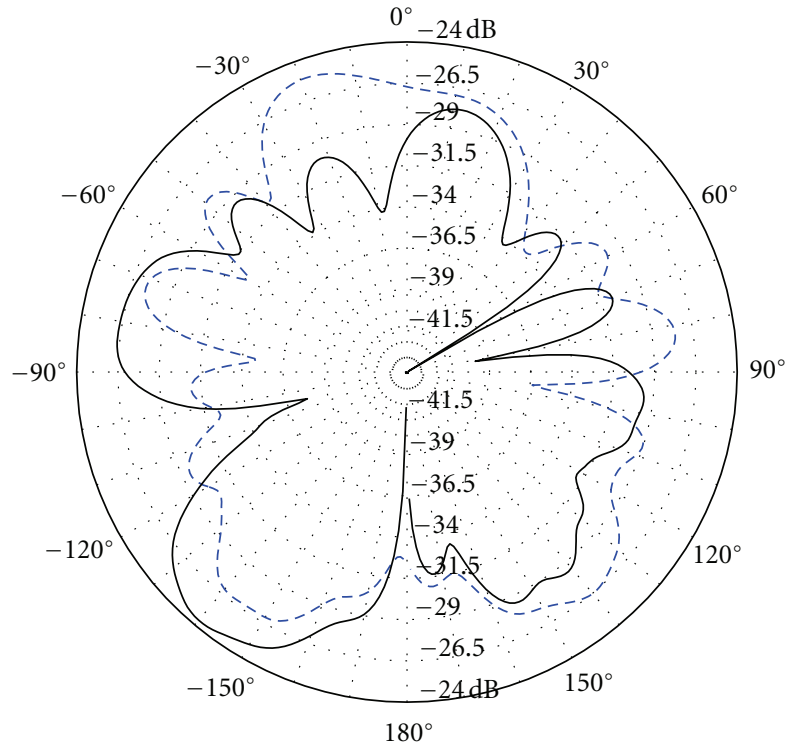

FIgure 7: Measured radiation pattern at $2.4 \mathrm{GHz}$ on $X Z$ plane (blue) and $Y Z$ plane (black).

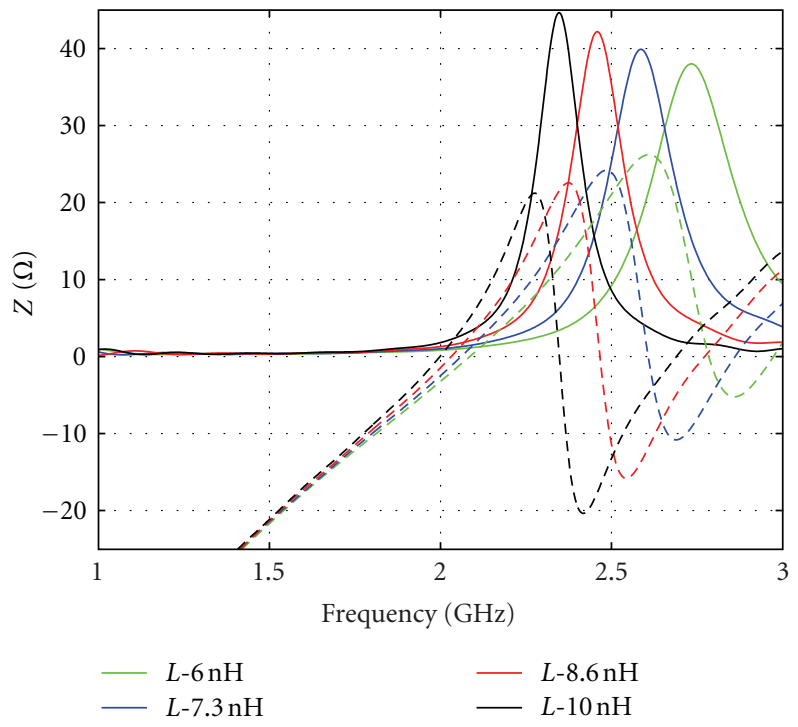

FIGURE 8: Frequency behavior of the real (solid lines) and imaginary (dashed lines) part of the antenna input impedance versus the inductance values of the chip inductor.

with respect to the performances predicted by the numerical simulation. However, this phenomenon is expected given the variations that can occur in the antenna behavior due to the PIN diode parasitic elements and to the dispersion of the inductor parameters.

Figure 8 shows the real and imaginary part of the antenna input impedance with respect to the chip inductor characteristics.

It is clear that for higher inductance values, the resonant frequency of the antenna is lower. Moreover, the bandwidth is also narrower. 


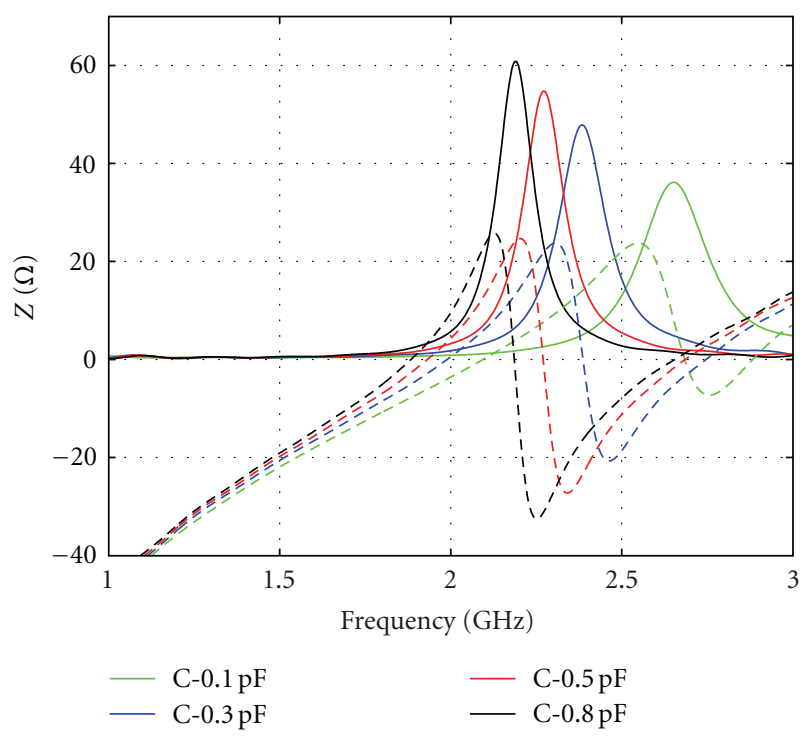

FIGURE 9: Frequency behavior of the real (solid lines) and imaginary (dashed lines) part of the antenna input impedance versus the PIN diode capacitance values.

Besides the inductor value, the diode capacitance also shows a large influence over the resonant frequency and bandwidth. Figure 9 shows the real and imaginary part of the antenna input impedance response as the capacitance value of the PIN diode increases.

The increased capacitance leads to a resonant frequency reduction and narrower bandwidth. Moreover, the effect of the capacitance on the impedance may lead to considerable mismatches, due to the increased value observed.

Besides the variations presented so far, the fact that the components are soldered to the radiating element of the antenna and also the diode polarization circuit, which may not present a perfect DC and RF signal isolation, might be possible causes for the antenna detuning.

\section{Conclusion}

In this paper a very small printed monopole antenna with frequency reconfiguration capability was presented, which uses PIN diodes as a key design strategy. It was shown that it is possible to use PIN diodes in conjunction with chip inductors, in order to obtain a very small antenna that can work in two different frequency bands. However, this results in a reduction of the gain and of the bandwidth of the considered antenna.

The design and sizing of this type of antenna are rather complex and all the parasitic characteristics of the different components must be known and taken into account, to make the best possible modeling of it. However this is not always possible. Little variations in the diode capacitance and inductance can change both of the resonant frequencies. Nevertheless, good agreements between the simulated and measured results were obtained, with a seemingly omnidirectional radiation pattern.

\section{Acknowledgments}

The authors acknowledge the Portuguese FCT/MCTES for financing the project PTDC/EEA-TEL/122681/2010PROENERGY-WSN-Prototypes for Efficient Energy SelfSustainable Wireless Sensor Networks.

\section{References}

[1] R. O. Ouedraogo, E. J. Rothwell, A. R. Diaz, K. Fuchi, and A. Temme, "Miniaturization of patch antennas using a metamaterial-inspired technique," IEEE Transactions on Antennas and Propagation, vol. 60, no. 5, pp. 2175-2182, 2012.

[2] S. S. Gaikwad, M. Singh, A. Ajey, and S. S. Karthikayen, "Size miniaturized fractal antenna for 2. $5 \mathrm{GHz}$ application," in Proceedings of the IEEE Students Conference on Electrical, Electronics and Computer Science, Bhopal, India, 2012.

[3] Q. Luo, J. R. Pereira, and H. M. Salgado, "Compact printed monopole antenna with chip inductor for WLAN," IEEE Antennas and Wireless Propagation Letters, vol. 10, pp. 880883, 2011.

[4] Q. Luo, H. M. Salgado, and J. R. Pereira, "Compact printed monopole antenna array for dualband WLAN application," in Proceedings of the International Conference on Computer as a Tool (EUROCON '11), pp. 1-4, Lisbon, Portugal, April 2011.

[5] G. Cappelletti, D. Caratelli, R. Ciccetti, and M. Simeoni, "A low-profile printed drop-shaped dipole antenna for wideband wireless applications," IEEE Transactions on Antennas and Propagation, vol. 59, no. 10, pp. 3526-3535, 2011.

[6] J. L. Volakis, Antenna Engineering Handbook, McGraw-Hill, 4th edition, 2007.

[7] Y. Tawk, J. Costantine, and C. G. Christodoulou, "A rotatable reconfigurable antenna for cognitive radio applications," in Proceedings of the IEEE Radio and Wireless Symposium (RWS '11), pp. 158-161, Phoenix, Ariz, USA, January 2011.

[8] M. Unlu, Y. Damgaci, H. S. Mopidevi, O. Kaynar, and B. A. Cetiner, "Reconfigurable, tri-band RF MEMS PIFA antenna," in Proceedings of the IEEE International Symposium on Antennas and Propagation (APS '11), Spokane, Wash, USA, 2011.

[9] N. Haridas, A. T. Erdogan, T. Arslan et al., "Reconfigurable MEMS antennas," in Proceedings of the NASA/ESA Conference on Adaptive Hardware and Systems (AHS '08), pp. 147-154, June 2008.

[10] R. Valkonen, C. Luxey, J. Holopainen, C. Icheln, and P. Vainikainen, "Frequency-reconfigurable mobile terminal antenna with MEMS switches," in Proceedings of the 4th European Conference on Antennas and Propagation (EuCAP '10), Barcelona, Spain, April 2010.

[11] Y. K. Park and Y. Sung, "A reconfigurable antenna for quadband mobile handset applications," IEEE Transactions on Antennas and Propagation, vol. 60, no. 6, pp. 3003-3006, 2012.

[12] M. I. Lai, T. Y. Wu, J. C. Hsieh, C. H. Wang, and S. K. Jeng, "Design of reconfigurable antennas based on an L-shaped slot and PIN diodes for compact wireless devices," IET Microwaves, Antennas and Propagation, vol. 3, no. 1, pp. 47-54, 2009.

[13] M. Komulainen, M. Berg, V. K. Palukuru, H. Jantunen, and E. Salonen, "Frequency-reconfigurable dual-band monopole antenna for mobile handsets," in Proceedings of the IEEE Antennas and Propagation Society International Symposium (AP-S '07), pp. 3289-3292, Honolulu, Hawaii, USA, June 2007.

[14] M. S. Nishamol, V. P. Sarin, D. Tony, C. K. Aanandan, P. Mohanan, and K. Vasudevan, "An electronically 
reconfigurable microstrip antenna with switchable slots for polarization diversity," IEEE Transactions on Antennas and Propagation, vol. 59, no. 9, pp. 3424-3427, 2011.

[15] A. Ghasemi, N. Ghavehchian, A. Mallahzadeh, and S. Sheikholvaezin, "A reconfigurable printed monopole for MIMO application," in Proceedings of the 6th European Conference on Antenas and Propagation (EUCAP '12), Prague, Czech Republic, 2012.

[16] D. E. Anagnostou and A. A. Gheethan, "A coplanar reconfigurable folded slot antenna without bias network for WLAN applications," IEEE Antennas and Wireless Propagation Letters, vol. 8, pp. 1057-1060, 2009.

[17] A. Ramadan, M. Al-Husseini, Y. Tawk, K. Y. Kabalan, and A. El-Hajj, "A novel frequency/pattern-reconfigurable microstrip antenna for WLAN applications," in Proceedings of the 4th European Conference on Antennas and Propagation (EuCAP '10), Barcelona, Spain, April 2010.

[18] "Coilcraft," SPICE Model for Coilcraft 0402HP, http:// www.coilcraft.com/pdf_viewer/showpdf.cfm?f=pdf_store: spice_0402hp.pdf.

[19] Avago Technologies, http://www.avagotech.com/pages/home/.

[20] W. E. Doherty Jr. and R. D. Joos, The Pin Diode Circuit Designer's Handbook, Microsemi Corporationc, 1st edition, 1998.

[21] “Avago Technologies," DATASHEET HSMP-386x, http://www .avagotech.com/docs/AV02-0293EN.

[22] R. C. Hansen, "Fundamental limitations in antennas," Proceedings of the IEEE, vol. 69, no. 2, pp. 170-182, 1981. 

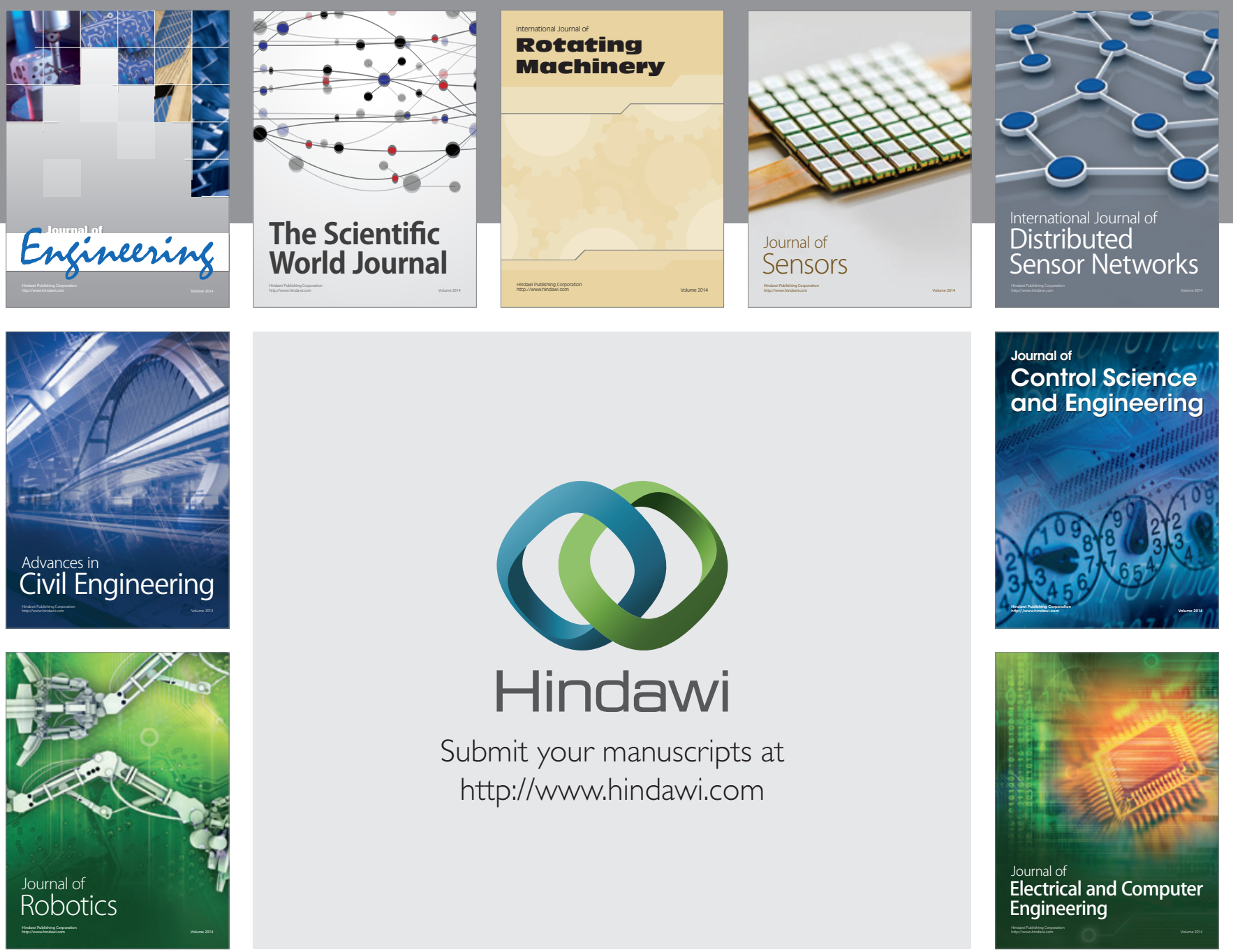

Submit your manuscripts at

http://www.hindawi.com
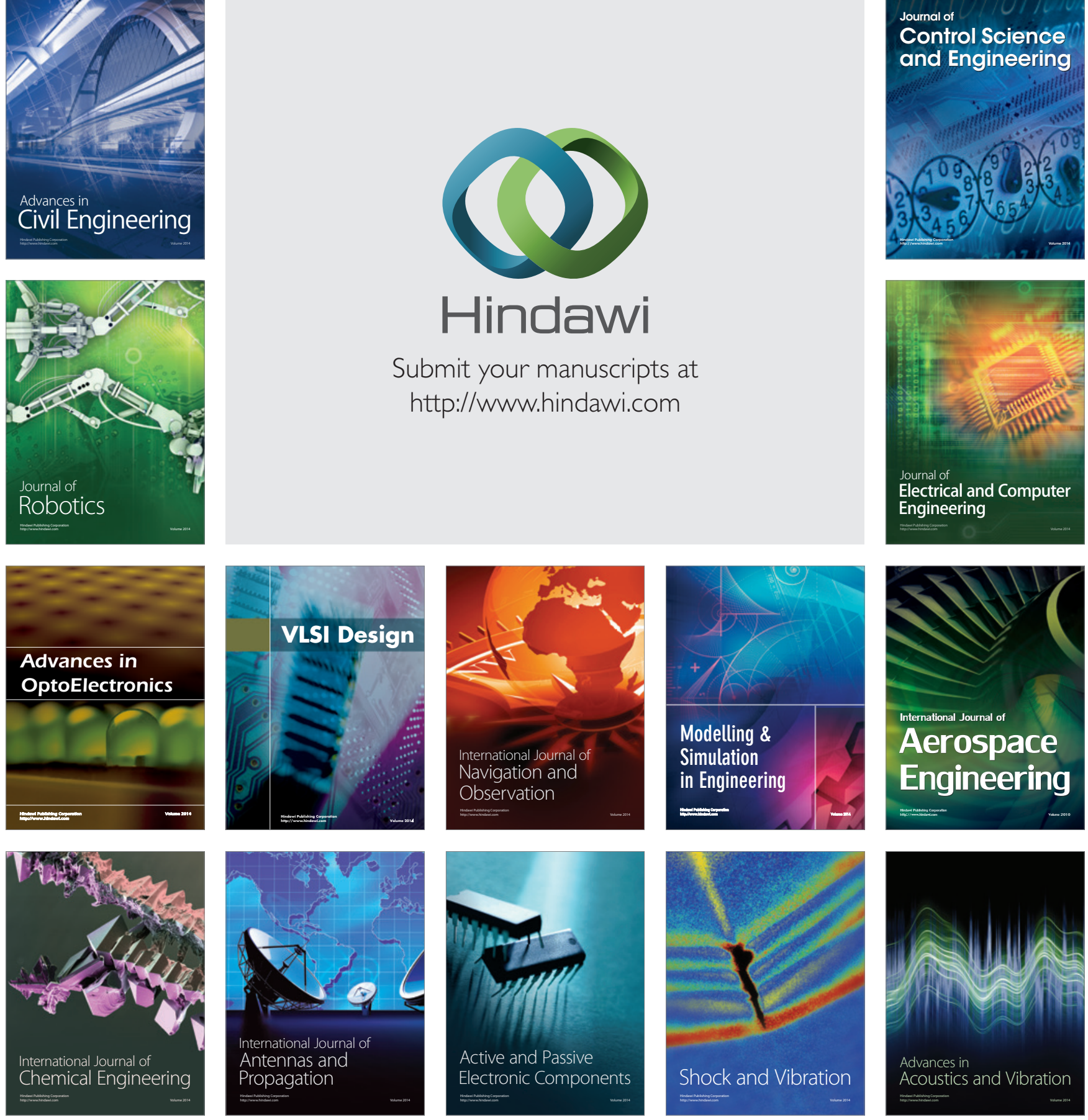